\title{
Gestational Trophoblastic Neoplasm pTX TNM Finding v8
}

National Cancer Institute

\section{Source}

National Cancer Institute. Gestational Trophoblastic Neoplasm pTX TNM Finding v8. NCI

Thesaurus. Code C140028.

Gestational trophoblastic neoplasm in which the primary tumor cannot be assessed.

(from AJCC 8th Ed.) 